THE INTERNATIONAL

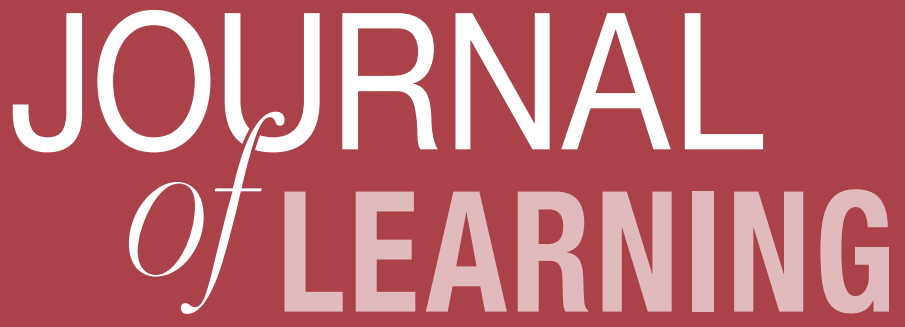

Volume 18, Issue 6

Comparing Students with Extreme Schematic Beliefs in Learning Mathematics Across Two Cultures

Clarence $\mathrm{Ng}$ 
THE INTERNATIONAL JOURNAL OF LEARNING

http://www.Learning-Journal.com

First published in 2012 in Champaign, Illinois, USA

by Common Ground Publishing LLC

www.CommonGroundPublishing.com

ISSN: $1447-9494$

(C) 2012 (individual papers), the author(s)

(c) 2012 (selection and editorial matter) Common Ground

All rights reserved. Apart from fair dealing for the purposes of study, research, criticism or review as permitted under the applicable copyright legislation, no part of this work may be reproduced by any process without written permission from the publisher. For permissions and other inquiries, please contact

<cg-support@commongroundpublishing.com>.

THE INTERNATIONAL JOURNAL OF LEARNING is peer-reviewed, supported by rigorous processes of criterion-referenced article ranking and qualitative commentary, ensuring that only intellectual work of the greatest substance and highest significance is published.

Typeset in Common Ground Markup Language using CGPublisher multichannel typesetting system

http://www.commongroundpublishing.com/software/ 


\title{
Comparing Students with Extreme Schematic Beliefs in Learning Mathematics Across Two Cultures
}

\author{
Clarence Ng, Griffith University, Queensland, Australia
}

\begin{abstract}
This paper extended the analyses of $\mathrm{Ng}$ (2005) and explored the differences between students with polarized schematic views in learning mathematics. Two groups of high school students from Hong Kong and Australia completed a questionnaire tapping their views on their cognitions of the self or academic self-schemas, achievement goals, learning approaches and anticipated performance. $\mathrm{Ng}$ (2005) located two groups of schematic students across both cultures demonstrating consistent characteristics in motivational and learning processes. The current investigation explored the differences between corresponding schematic groups found in this previous study. It was found that positive schematic students in Hong Kong are less schematicised than Australian students. In contrast, negative schematic students in Hong Kong were more schematicized than their Australian counterparts. These differences in the development of schematicised selves among students in two different cultures could be attributed to the difference in evaluation practice in two different educational systems. The results draw our attention to teaching and learning processes in schools and call for more reformative effort in Mathematics learning in order to prevent premature dropping of the subject due to the development of a negative self.
\end{abstract}

Keywords: Self-schema, Motivation, Learning Approaches, Mathematics, Hong Kong, Australia

\section{Introduction}

$\mathrm{E}$

DUCATIONAL RESEARCHERS IN developed countries such as Britain and Australia have researched into various issues related to the declining enrolment in school Mathematics and related science subjects (e.g. McPhan, et al, 2008; Reiss et al., 2011). Mathematics and science educators, researchers and policy makers have therefore focused on promoting students' uptake of these subjects (cf. European Commission, 2004). However, the declining trend of enrolment in Mathematics has not been reversed (e.g. Van Langen, Rekers-Mombarg, \& Dekkers, 2008). The important question is therefore what motivates students to engage in learning mathematics in such as a way that they will be drawn close to this subject and be willing to continue taking it in their senior studies. While a major research concentration has focused our attention on the importance of personal factors such as gender and ethnicity (Uerz, Dekkers, \& Beguin, 2004; Watt, 2004), a plethora of research has investigated the effects of various cognitive factors, such as self-efficacy (e.g. Nagy, et al., 2010), perceived difficulties (e.g.; Crombie et al., 2005; Muzzatti \& Agnoli, 2007), and valuing of mathematics (e.g. Eccles et al., 1985; Watt, 2004), on students' subject choice. The current study added to this literature base. It investigated an under-researched cognitive construct, academic self-schema, and used it to understand contrasting motivational and learning patterns in Mathematics using student samples drawn from culturally different countries. 
Aligning with the work of Markus (1977), an academic self-schema is defined as students' cognitive generalizations of their selves derived from past learning experiences, which functions to guide students' cognitive, affective and behavioural responses in learning. Like other self-schemas, an academic self-schema is experience-based and developed through repeated evaluation of one's past learning experiences within a specific learning domain. To have an academic self-schema in a learning domain, one must feel that these past learning experiences are personally significant and construct their core identity on this specific domain. The current study focused on the learning of Mathematics and assumed that students with a favourable academic self-schema in this school discipline will consider Mathematics learning as self-descriptive and personally important.

This study extended the analysis of a previous investigation on students' academic selfschemas (Ng, 2005). This previous study verified the concept of academic self-schema using culturally different samples. However it did not investigate the issue of important crosscultural differences. The current study assumed that students' academic self-schemas and their corresponding learning patterns will be influenced by values, norms and practices within specific cultural and educational systems. Therefore, comparing students with similar academic self-schemas across contrasting cultures will be able to add to our limited knowledge about academic self-schemas and their development (cf. Pintrich, 1994). The present study reanalysed the data collected in this previous study and examined the possible differences between corresponding schematic groups of students from these two cultures. This study was significant as it was the first study comparing Australian and Chinese students based on the concept of academic self-schemas.

\section{The Self-schema Concept and Research}

The study of self-schema began with Markus' seminal study (1977) on dependence and interdependence schema. According to Markus, self-schemas are "cognitive generalizations about the self, derived from past experience that organize and guide the processing of selfrelated information" (Markus, 1977, p. 64). Developed on the basis of past experiences, self-schemas provide an organised way to process self-related information, mediate and regulate behaviours (Alexander, 1997; Cross \& Markus, 1994; Oyserman \& Markus, 1993). Social psychological studies found that individuals with a self-schema in a specific personality domain will process self-related information faster and cite more behavioural examples related to it (e.g. Markus, 1977). Self-schemas also influence perceptions about others as these self-identities are used to make sense of social situations and ambiguous social information (Catrambone \& Markus, 1987; Lewicki, 1984; Markus \& Smith, 1981). More recent studies in applied social psychology such as appearance schemas (e.g. Jung \& Lennon, 2003) and exerciser's schemas (e.g. Banting, Dimmock, \& Lay, 2009) have focused on understanding the relationship self-schemas and behavioural consequences. For example, Kendzierski investigated the relationship between self-schemas and costly health behaviours (Kendzierski, 1988, 1990) and found that individuals with a self-schema on exercise were more likely to act on their exercising intentions and plans (Kendzierski \& Whitaker, 1997). Another example can be found in the studies of cross-cultural self-contruals; Hannover and Kuhnen (2004) found that individuals from collectivistic and individualistic societies responded differently to social information related to independence and interdependence and explained their dif- 
ferential pattern in terms of corresponding self-knowledge and modes of thinking associated cultural selves developed within a specific society.

The application of the self-schema concept to the research on motivation and learning, however, remains limited (Murphy \& Alexander, 2000). Among educational researchers, Garica and Pintrich (1994) pioneered a working model for understanding self-schemas in education. Self-schema is conceptualized as a composite construct comprising of four complementing dimensions namely, affect, temporality, importance and efficacy. The affect dimension denoted that people's affective state is influenced by their current self-schema. The temporal dimension distinguishes between the past, present and future selves. The value dimension focuses on the centrality and importance of a self-schema in defining one's identity or core conception. The efficacy dimension refers to the belief that one has the ability to attain, maintain or avoid a particular self-conception. They utilized this model to study a 'good student' versus a 'bad student' self-schema (Garica \& Pintrich, 1993). The findings showed that students who embraced a 'good student' self-schema were more likely to exert volitional control on their learning and usually had better school results than were those holding a 'bad student' self-schema.

\section{Positive and Negative Schematics}

$\mathrm{Ng}$ (2005) utilised this multidimensional model and examined its validity for studying academic self-schemas for learning mathematics using culturally contrasting samples. Using a Chinese sample from Hong Kong, $\mathrm{Ng}$ (2005) located two contrasting groups of students holding positive and negative self-schemas in learning mathematics. In addition, these contrasting groups of schematic students differed from each other in the use of achievement goals, approaches to learning, and expected levels of performance. These findings were validated and extended in using a culturally different sample, Australian students. Again, cluster analyses successfully classified Australian participants into positive and negative schematic clusters. It was also found that these two groups of schematic students approached learning mathematics in a self-congruent manner similar to those found among the Chinese participants. The converging results lent empirical support to the theoretical formulation of positive and negative schematic students and the validity of using the self-schema concept to investigate motivation and learning.

Positive schematic students consider mathematical learning and achievement as an idiosyncratic salient part of the self. Therefore, to maintain this desirable self-conception, they would learn mathematics with achievement goals and learning approaches that secure comprehension and mastery, and help them get a good result. Negative schematic students consider mathematical learning as a threat to their general well-being. Learning mathematics is a part of the self that always associated with fear, embarrassment, and anxiety. Therefore, students with such a negative view will probably take on achievement goals and learning approaches that disengage them from learning mathematics, rendering their learning pattern similar to students suffering from learned-helplessness.

This study provided empirical evidence verifying the concept of self-schema for classifying students in positive and negative schematics based on four dimensions. However, this study did not continue to examine the differences between corresponding schematic groups from these two contrasting cultures. It is problematic to assume that positive schematic students (and their negative counterparts) from both cultures will have a similar level of endorsement 
in these four complimentary dimensions of an academic self-schema. Likewise, it is unlikely that students in the corresponding schematic groups from these two cultures will engage in learning mathematics in an identical manner.

Both Chinese and Australian students are expected to master important mathematical skills and knowledge and to perform well in this important school discipline. However, the contrasting cultural and educational systems in these two countries will have their own unique standard governing how a student can be regarded as an achieving mathematics learners and in what ways such a standard can be met. In a current review of research on culture and self, Markus and Kitayama (2010, p. 422) stated that cross-cultural studies on the self "in different regions of the world have revealed differences in the selves, or differences in patters of attuning to contexts". For example, Kobal and Musek (2001) attributed differences in academic self-concepts between French and Slovenian students to the differential practices in these two educational systems. Cross-cultural studies involving Chinese and Australian students showed that these two groups of students developed within culturally different societies with varying values, norms and socialisation processes (Markus \& Kitayama, 1991; Triandis, 1989). Cultural differences will result in a different prescription of accepted attributes and how these attributes should be developed. For example, crosscultural studies (Hannover \& Kuhnen, 2004) on self-construals found that participants coming from individualistic and collectivistic societies responded differently to information stimuli, which was attributed to differential content and thinking processes associated with specific cultural selves.

Based on individualistic norms and values, positive schematic students in Australia may have a higher level of endorsement of individual schematic dimensions related on enjoyment, efficacy and future planning than do their counterparts from Hong Kong. In contrast, Hong Kong students may focus more on importance in crafting their positive schematic views as these students are required to meet the expectation of significant others. Students will probably engage in different learning patterns as a result of differences in cultural and educational practices, values and norms. In fact, studies comparing the learning processes of Chinese students versus Australian students found that these two groups of students differ in terms of their leaning approaches (e.g. Biggs, 1987), effort versus ability attribution (e.g. Hau \& Salili, 1991), and learning conceptions (e.g. Chan, 1999). These cross-cultural studies on learning involving students from these two countries provide empirical support for the hypothetical differences between corresponding schematic students in these two cultures.

Based on these considerations, this study examined two hypotheses:

1. Corresponding schematic students from these two cultures would endorse a different level of enjoyment, importance, efficacy and future planning related to mathematics;

2. Corresponding schematic students from these two cultures would show a different pattern of learning engagement and performance anticipation.

\section{Method}

\section{Participants}

This study involved two cohorts of Year 10 students, drawing from high schools in Hong Kong and Brisbane. The Hong Kong cohort contained 329 Chinese students. These students 
included $143(43.7 \%)$ males and $183(56 \%)$ females and had a mean age of 15.36 . The Australian cohort was comprised of 582 students with a mean age of 14.66 years. There were $276(47.4 \%)$ females and $303(52.1 \%)$ males; $3(0.5 \%)$ students did not provide any information regarding their gender. Students in both cohorts had mixed achievement levels. For the Chinese students, the Mathematics subject was compulsory for a major public examination that they were required to sit for in the following year. As for the Australian students, Year 10 was the final year in which the learning of Mathematics was compulsory and by the end of Year 10, they were allowed to select different streams of Mathematics for their senior studies.

\section{Measures}

Students in both cohorts completed an identical questionnaire that assessed academic selfschemas, achievement goals, learning approaches and anticipated performance. All items were set in a 5-point Likert scale, ranging from strongly disagree (1) to strongly agree (5), or in the case of measuring learning approaches, very untrue of me (1) to very true of me (5).

The Table 1 shows the brief definition for these variables, sample items and reliability scores for both cohorts. Items assessing achievement goals were taken from previous studies (e.g. Ames, 1992; Dowson \& McInerney, 2001, Meece, Blumenfeld \& Hoyle, 1988; Young, 1997). Items assessing function goals were written specifically for this study (cf. Wigfields $\&$ Eccles, 1992). The Chinese study used a performance goal scale combining both approaching and avoidance orientations as it was conducted prior to the academic debate resulting in the separation of performance goals into two finer categories. The performance scale for the Australian sample focused on the approaching orientation. Learning approaches were assessed using Mathematics Learning Process Questionnaire (MLPQ, Liu, 1997), which was an adapted version of the Learning Process Questionnaire developed by Biggs (1987). New items were developed specifically to assess the four dimensions - affect, efficacy, importance and future self (Garcia \& Pintrich, 1994) — of students' academic self-schemas. For a detailed discussion of these variables, please consult $\mathrm{Ng}$ (2005). 
Table 1: Construct, Variables, Items and Reliability Scores

\begin{tabular}{|c|c|c|c|}
\hline Construct & Definition and Sample Items & $\begin{array}{l}\text { Reliability } \\
\text { Score }(\alpha) \\
\text { Chinese } \\
\text { Sample }\end{array}$ & 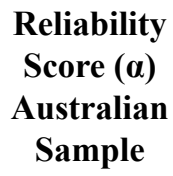 \\
\hline $\begin{array}{l}\text { Academic } \\
\text { self-schema }\end{array}$ & \multicolumn{3}{|c|}{$\begin{array}{l}\text { Students' cognitive generalizations of their selves derived from past } \\
\text { learning experiences in Mathematics }\end{array}$} \\
\hline affect & $\begin{array}{l}\text { Students' enjoyment and fun derived from } \\
\text { learning mathematics; Sample item: "I enjoy } \\
\text { learning mathematics" }\end{array}$ & .63 & .80 \\
\hline Efficacy & $\begin{array}{l}\text { Students' ability and effort expenditure in do- } \\
\text { ing mathematics; Sample item: "I'm as smart } \\
\text { as others in doing mathematics"' }\end{array}$ & .76 & .69 \\
\hline Importance & $\begin{array}{l}\text { Students' value attach to their Maths self- } \\
\text { conception; Sample item: "It is important for } \\
\text { me to do well in mathematics" }\end{array}$ & .83 & .71 \\
\hline Future planning & $\begin{array}{l}\text { students' perceived future selves in learning } \\
\text { mathematics; Sample item: "I'll choose to } \\
\text { study mathematics or other related subjects in } \\
\text { my future studies" }\end{array}$ & .74 & .74 \\
\hline $\begin{array}{l}\text { Achievement } \\
\text { goals }\end{array}$ & \multicolumn{3}{|c|}{ Students' perceived purposes for learning a specific subject } \\
\hline Mastery goals & $\begin{array}{l}\text { Engaging in learning mathematics in order to } \\
\text { achieve a better understanding and improve } \\
\text { mastery; Sample item: "I want to master differ- } \\
\text { ent mathematical skills" }\end{array}$ & .82 & .66 \\
\hline $\begin{array}{l}\text { Relative Per- } \\
\text { formance goals }\end{array}$ & $\begin{array}{l}\text { Engaging in learning mathematics in order to } \\
\text { demonstrate one's ability; Sample item: "I } \\
\text { want to get better results" }\end{array}$ & .82 & .78 \\
\hline Functional goals & $\begin{array}{l}\text { Engaging in learning mathematics in order to } \\
\text { utilize the knowledge for academic promotion } \\
\text { or career entry; Sample item: "I need to do } \\
\text { well in mathematics in order to get into the } \\
\text { university program that I want" }\end{array}$ & .66 & .77 \\
\hline \begin{tabular}{l|}
$\begin{array}{l}\text { Social solidarity } \\
\text { goals }\end{array}$ \\
\end{tabular} & $\begin{array}{l}\text { Engaging in learning mathematics in order to } \\
\text { help each other; Sample item: "I want to help } \\
\text { my friends to learn mathematics" }\end{array}$ & .67 & .77 \\
\hline
\end{tabular}




\begin{tabular}{|l|l|c|c|}
\hline $\begin{array}{l}\text { Approaches to } \\
\text { Learning }\end{array}$ & $\begin{array}{l}\text { Students' predispositions to particular intentions and strategies in } \\
\text { learning }\end{array}$ & .82 \\
\hline Deep approach & $\begin{array}{l}\text { Involving intrinsic motivation and strategies se- } \\
\text { curing understanding; Sample item: “In studying } \\
\text { a new topic in maths, I often recall materials I } \\
\text { have learned and see if there is a relationship } \\
\text { between them" }\end{array}$ & .73 & .86 \\
\hline $\begin{array}{l}\text { Achieving } \\
\text { approach }\end{array}$ & $\begin{array}{l}\text { Involving a strong desire for achievement and } \\
\text { strategies securing good results; sample item: } \\
\text { "I'll work for top mark in maths whether or not } \\
\text { I like the subject" }\end{array}$ & .86 \\
\hline $\begin{array}{l}\text { Surface } \\
\text { approach }\end{array}$ & $\begin{array}{l}\text { Involving extrinsic motivation and surface } \\
\text { strategies like rote learning and memorization; } \\
\text { sample item: "In maths, I only do enough to get } \\
\text { a pass and no more" }\end{array}$ & .70 \\
\hline
\end{tabular}

Due to administrative constraints, students' actual grades were not available for assessment in this study. This study compared students' anticipated grades. As self-schemas are considered to have filling-in effects (Markus \& Smith, 1981), it is advisable to examine the relationship between students' academic self-schemas in learning mathematics and their predicted levels of performance. Students were asked to rate their possible mark at the end of the academic year using a 6-point scale (A, B, C, D, E and No target grade). As no student chose the 'No Target Grade' response, the scale was transformed to a 5-point scale $(A=5$, $\mathrm{E}=1)$.

\section{Schematic Groups}

Using hierarchical cluster analysis, $\mathrm{Ng}$ (2005) located two contrasting groups of schematic students in both Chinse and Australian samples. For the details regarding the clustering procedures, analyses and verification, please consult this previous study. The following section describes these resulting clusters. Table 2 shows the descriptive statistics.

Table 2: A Comparison of Positive and negative Schematics in both Samples

\begin{tabular}{|c|c|c|c|c|}
\hline & $\begin{array}{c}\text { Affect } \\
\text { Mean (SD) }\end{array}$ & $\begin{array}{c}\text { Efficacy } \\
\text { Mean (SD) }\end{array}$ & $\begin{array}{l}\text { Importance } \\
\text { Mean (SD) }\end{array}$ & $\begin{array}{c}\text { Future } \\
\text { Mean (SD) }\end{array}$ \\
\hline \multicolumn{5}{|l|}{ Chinese students } \\
\hline Negative schematics $(\mathrm{N}=91)$ & $2.05(.67)$ & $1.99(.50)$ & $2.39(.73)$ & $1.99(.67)$ \\
\hline Positive schematics $(\mathrm{N}=236)$ & $3.73(.63)$ & $3.22(.50)$ & $3.52(.67)$ & $3.20(.64)$ \\
\hline \multicolumn{5}{|l|}{ Australian students } \\
\hline Negative schematics $(\mathrm{N}=207)$ & $1.98(.76)$ & $2.52(.59)$ & $2.44(.56)$ & $2.61(.51)$ \\
\hline Positive schematics $(\mathrm{N}=375)$ & $3.24(.89)$ & $3.40(.62)$ & $3.67(.56)$ & $3.89(.53)$ \\
\hline
\end{tabular}


The negative cluster group represented students with a negative self-schema in learning mathematics. Both Chinese and Australian students in this group found learning mathematics uninteresting ( $\bar{X}$ for affect=2.05 and 1.98 for Australians and Chinese respectively). They were unwilling to put effort into the subject and held a low sense of efficacy in learning mathematics ( $\bar{X}$ for efficacy=1.99 for Chinese and 2.52 for Australians). Expectedly, they did not take successful learning of mathematics as important for them ( $\bar{X}$ for importance $=2.38$ for Chinese and 2.44 for Australians) and did not plan to do more mathematics in the future ( $\bar{X}$ for future $=2.13$ for Chinese and 2.61 for Australians).

The positive group showed a contrasting pattern of self-cognitions. Students in the positive groups across both cultures enjoyed learning mathematics ( $\bar{X}$ for affect $=3.73$ for Chinese and 3.24 for Australians). They were willing to put effort into this subject and considered themselves capable ( $\bar{X}$ for efficacy 3.22 for Chinese and 3.40 for Australians). They also considered mathematics learning important $(\bar{X}$ for importance $=3.52$ for Chinese and 3.67 for Australians) and prepared to do more mathematics in the future ( $\bar{X}$ for future self $=3.20$ for Chinese and 3.89 for Australians).

\section{Result}

\section{Differences in Schematic Dimensions}

To test the difference among these four groups of schematic students, a MANOVA analysis was first conducted to examine the difference in terms of the clustering measures. A MANOVA analysis was conducted for detecting the difference between negative schematic group of the Chinese sample and that of the Australian sample. Likewise another MANOVA analysis tested the difference between two positive schematic groups. Post hoc difference was assessed by Scheffe test.

The result of these analyses showed that corresponding schematic groups in both samples were different from each other despite that they showed the same schematic properties. The Australian positive schematic group was different from the Chinese positive schematic group along the clustering measures in combination $(F=95.45$; d.f $=4,606 ; p<.001)$. Similarly, the Australian negative schematic group was different from the Chinese counterpart $(F=37.35$; d.f. $=4,293 ; p<.001)$ in the four clustering dimensions.

Regarding the positive schematics, univariate F-tests confirmed that Australian and Chinese students differed in all the measuring dimensions. The negative schematics in both samples differed only in efficacy and future-self dimension. Table 3 shows the results of univariate F-tests. 
Table 3: Univariate F-ratios from Both Studies

\begin{tabular}{|l|c|c|}
\hline Clustering measures & $\begin{array}{c}\text { Positive Schematic } \\
\text { (F-ratio) }\end{array}$ & $\begin{array}{c}\text { Negative Schematic } \\
\text { (F-ratio) }\end{array}$ \\
\hline Affect & $54.47^{* *}$ & .49 (NS) \\
\hline Efficacy & $13.63^{* *}$ & $49.43 * *$ \\
\hline Importance & $210.67^{* *}$ & $.49(\mathrm{NS})$ \\
\hline Future-self & $9.15^{*}$ & $73.65^{*}$ \\
\hline Note: NS=nonsignificant; ${ }^{*} p<.01, * * p<.001$ & \\
\hline
\end{tabular}

Table 4 compares the means among these schematic groups in four clustering measures. As shown, Australian positive schematics had a higher score on efficacy, future self and importance dimensions, while the Chinese positive schematics had a higher score on the affect dimension. Similar findings, yet in a reverse direction, were noted with the negative schematics. The Australian negative schematics relative to the Chinese ones had higher scores in efficacy and future-self dimensions. These two groups of negative schematic students did not differ in the rest two clustering measures.

Table 4: Differences among Schematic Groups of both Samples

\begin{tabular}{|l|c|c|c|c|}
\hline $\begin{array}{l}\text { Clustering } \\
\text { Measures }\end{array}$ & \multicolumn{2}{|c|}{ Positive Schematics } & \multicolumn{2}{c|}{ Negative Schematics } \\
\hline & Australian & Chinese & Australian & Chinese \\
\hline Affect & $3.23^{*}$ & $3.73^{*}$ & $1.98(\mathrm{NS})$ & $2.05(\mathrm{NS})$ \\
\hline Efficacy & $3.40^{*}$ & $3.23^{*}$ & $2.51^{*}$ & $1.99 *$ \\
\hline Importance & $3.66^{*}$ & $3.52^{*}$ & $2.44(\mathrm{NS})$ & $2.39(\mathrm{NS})$ \\
\hline Future self & $3.89^{*}$ & $3.17^{*}$ & $2.16^{*}$ & $1.99^{*}$ \\
\hline Note: $* \mathrm{p}<.001 ; \mathrm{NS}=$ nonsignificant \\
\hline
\end{tabular}

\section{Differences in Learning Engagement and Performance Anticipation}

Subsequently, another set of MANOVA tests were conducted to see if these two groups of positive schematic students would be different from each other in terms of their learning goals, learning approaches and anticipated year-end performance. The same analytical procedure was repeated with the two negative schematic groups. It was assumed that there would be a major difference in learning engagement patterns between the two corresponding schematic groups, despite that they were classified and labeled as having identical schematic properties.

\section{Positive Schematics}

Results showed that Australian positive schematics differed from the Chinese ones in their learning engagement pattern $(F=108.65$; d.f. $=8.602 ; p<.001)$. The univariate test revealed that these two schematic groups differed in terms of deep approach, achieving approach, 
functional goals, social goals, performance goals and the level of anticipate performance. However, they did not differ in mastery goals and surface approach. Table 5 shows the univariate $\mathrm{F}$-test results.

In terms of learning goals, no difference was found between the two groups in mastery goal. However, the positive schematics in Australia endorsed more functional goals while the Chinese schematics used more performance goals and social solidarity goals.

Table 5: Differences between Australian and Chinese Positive Schematics

\begin{tabular}{|l|r|c|c|}
\hline $\begin{array}{l}\text { Learning Engagement } \\
\text { Variables }\end{array}$ & F-test & $\begin{array}{c}\text { Australian Positive } \\
\text { Schematics (Means) }\end{array}$ & $\begin{array}{c}\text { Chinese Positive } \\
\text { Schematics (Means) }\end{array}$ \\
\hline Achieving approach & $84.05^{*}$ & 3.74 & 3.29 \\
\hline Deep approach & $235.10^{*}$ & 3.16 & 2.44 \\
\hline Surface approach & $\mathrm{NS}$ & 2.68 & 2.63 \\
\hline Mastery goal & $\mathrm{NS}$ & 3.41 & 3.51 \\
\hline Performance goal & $38.53^{*}$ & 3.20 & 3.64 \\
\hline Functional goal & $66.93^{*}$ & 3.97 & 3.40 \\
\hline Social-solidarity goal & $148.95^{*}$ & 2.46 & 3.23 \\
\hline Anticipated Performance & $188.77^{*}$ & 3.80 & 2.68 \\
\hline Note $*$ p $<.001 ;$ NS=nonsignificant. & \\
\hline
\end{tabular}

As shown in Table 5, the Australian positive schematics, relative to the Chinese ones, endorsed the use of deep and achieving approaches more strongly. Notably, the difference between these two positive schematic groups was extremely strong in the deep approach (note the Fscore). It is then not surprising to find that Australian positive schematics showed a higher expectation for a better year-end grade than did the Chinese.

\section{Negative Schematics}

The Australian negative schematics differed from their Chinese counterparts in their learning engagement $(F=45.47$; d.f. $=8,289 ; p<.001)$. The differences were located in the three learning approaches, social solidarity goals and anticipated performance. Table 5 shows the univariate F-test results and the means for the learning engagement variables.

Table 6 shows that the Australian negative schematics had a relatively higher score in the deep and achieving approaches but a lower score in the surface approach than did the Chinese negative schematics. These indicate that with regard to the use of learning approaches, negative schematics in Australian were not as maladaptive as the Chinese negative schematics in Hong Kong. Consequently, the Australian negative schematics demonstrated a relatively stronger score in anticipated performance than did the Chinese negative schematics. 
Table 6: Differences between Australian and Chinese Negative Schematics

\begin{tabular}{|l|c|c|c|}
\hline $\begin{array}{l}\text { Learning Engagement } \\
\text { Variables }\end{array}$ & F-test & $\begin{array}{c}\text { Australian Negative } \\
\text { Schematics }\end{array}$ & $\begin{array}{c}\text { Chinese Negative } \\
\text { Schematics }\end{array}$ \\
\hline Achieving approach & $79.99^{*}$ & 3.24 & 2.54 \\
\hline Deep approach & $79.04^{*}$ & 2.52 & 1.83 \\
\hline Surface approach & $15.07^{*}$ & 2.95 & 3.25 \\
\hline Mastery goal & $\mathrm{NS}$ & 2.59 & 2.56 \\
\hline Performance goal & $\mathrm{NS}$ & 3.01 & 3.20 \\
\hline Functional goal & $\mathrm{NS}$ & 2.77 & 2.59 \\
\hline Social-solidarity goal & $30.38^{*}$ & 2.15 & 2.70 \\
\hline Anticipated Performance & $174.45^{*}$ & 2.91 & 1.59 \\
\hline Note: ${ }^{*} \mathrm{p}<.001 ;$ NS=nonsignificant. & & \\
\hline
\end{tabular}

The two groups, however, showed no significant difference in learning goals. The only exception was found in the social solidarity goal; of which, the Chinese negative schematics showed relatively higher scores than the Australians, which may be attributed to the collectivistic nature of the Chinese societies.

\section{Discussion}

The current results showed important differences among corresponding schematic groups in Australia and Hong Kong. Australian positive schematics had higher scores in efficacy, importance and future planning while their Chinese counterparts scored higher on the affect dimension only. As for the negative schematics, Chinese students had lower scores in efficacy and future planning as compared to their counterparts in Australia. In general, this pattern of findings indicates that Australian positive schematics had a stronger affirming self in learning Mathematics while Chinese negative schematics had a stronger negative self in learning this subject. A follow-up ANOVA analyses based on the aggregate scores on four dimensions confirmed that these four schematic groups were different from each other ( $F=418.06$; d.f. $=3,908 ; p<.0001)$. Overall, the Chinese schematics oriented towards the negative side while Australian schematics oriented towards the positive end. In other words, Australian positive schematics were more positive than did the Chinese ones. The Chinese negative schematics, however, were more negative than their Australian counterparts. These results indicate a different degree of schematization, which is reflected in terms of the strength of students' responses to questionnaire items assessing these four complementing dimensions of academic self-schemas.

The differential degree of schematized selves in these schematic groups manifested in their learning engagement patterns. With stronger positive schematic selves, the Australian students relative to the Chinese students showed stronger endorsement on the use of deep and achieving approaches, which in turn could explain why they expected themselves to get a relatively higher grade at the end of the year than did the Chinese students. Australian 
students' stronger positive schematic self was also expressed through a stronger endorsement of functional goals, in which the Chinese positive schematics showed a lower score.

Concerning the negative schematics, the Chinese group showed a more elaborated negative self in learning mathematics. This strong negative self was associated with the endorsement of the use of a surface approach. Compared to their Australian counterparts, the Chinese negative schematic group used less of deep and achieving approaches. Consequently, the stronger negative self among the Chinese was associated with a lower expectation of performance. The social solidarity goal was the only achievement goal in which difference was recorded between the Australian and the Chinese negative schematics. This may be related to the collectivistic culture prevailing in Chinese societies (Markus \& Kitayama, 1991).

In general, these findings painted a gloomier picture for the Chinese negative schematics in Hong Kong when compared with their Australian counterparts. The negative schematics in Hong Kong thought they had a lower efficacy level and a weaker future self in learning mathematics than did the Australian negative schematics. In other words, the Chinese negative schematics showed a lower level of persistence when facing difficulties as they judged that effort would not help much in overcoming hurdles in learning mathematics. Neither did they believe in their ability. Subsequently they did not expect themselves to do well in the future. They would definitely not look forward to learning more mathematics.

In contrast, a brighter picture was portrayed for the Australian positive schematics when compared with the Chinese equivalents. The Australian positive schematics showed a higher level of efficacy belief, a stronger sense of importance and a clearer future-self in learning mathematics. In other words, the Australian positive schematics demonstrated a stronger schematized positive self.

The important questions arisen from the above discussion are: Why did positive schematics in Australia have a stronger positive self than their Chinese counterparts? In addition, what makes the negative schematics in Hong Kong develop a stronger negative self in learning mathematics than that shown by the Australian group? The discussion below provides tentative answers to these questions in the light of self-schema development.

Self-schema is developed through repeated evaluation of one's past experiences in a domain into an organized and networked self-knowledge (Markus, 1977). Therefore, the differential degree of schematized selves among the schematic groups in these two samples can be explained by the nature of evaluation regarding the learning of mathematics in these two countries.

Within educational contexts in these two cultures, evaluative information of oneself in learning mathematics can be gathered through parental expectation, opportunities and pathways endorsed by the society as a whole, and most importantly, the nature of performance feedback in terms of grading and marks in school. The nature of evaluation includes dimensions such as frequency, purpose and social significance.

In Hong Kong, evaluation comes not only from school, social comparison among peers and family members exerts great pressure on students for relative achievement (Biggs, 1996). Hong Kong, despite its internationalisation, is still a Chinese society built around Confucian values about education. Learning for the sake of meeting parental expectation is still a main motivation behind students' learning and achievement. Academic achievement is generally considered as the most important way to future success and therefore students compete fiercely with each other in order to gain a place in University education $(\mathrm{Ng}, 2009)$. 
At the classroom level, the Hong Kong system relies heavily on public examination for streaming students into different educational pathways. Competitive performance has always been a way for assessing students. In general, the purpose of these evaluative practices is driven overtly by summative and selective purposes (Hamo-Lyons, 1999). In other words, assignments, tests and examinations are often designed not for checking students' mastery or understanding but for normative comparison. It is therefore unsurprisingly to find that the Chinese students did not rate themselves in terms of efficacy and performance anticipation as high as their Australian counterparts across both schematic groups. Inevitably, these school practices and social mores hasten the process of the development of negative self-schemas as few students can be rewarded in a highly competitive and selective school system. In fact, most students are condemned by the normative assessment practice as "failures".

The Australian system is underpinned by a different set of cultural values, norms and beliefs. Aligning with other individualistic societies, the Australian culture values individual development and achieving one's potentials in different areas. Students have diverse pathways to success. Academic excellence while considered important, students can find less conventional way (but equally valued) to achieve their personal goals through technical education and different types of apprenticeship programs. Excellence in other areas, such as sports, music, the arts, and craftsmanship and trades are recognised pathways to future success. The Queensland education system in Australia places less stress on evaluation for selection or summative purposes. Students are not examined for promotion purposes. In principle, every student can study from year 1 to year 12 without much exposure to normative examination, except sitting for the national testings on literacy and numeracy. They are not required to sit for any high stake examination for university entry. Students' performance is assessed continuously over an extended period of two years to determine their Overall Position (OP) scores for entry into tertiary education. Assessment is entirely school-based, although there is a system of moderation using external panels to ensure comparability of standards in each subject across the state. Students are given an appropriate assignment load for the purpose of mastery, and progressive assessment is very much a characteristic of Queensland education.

More importantly, teachers, peers and parents put more stress on broad personal development in different life aspects, and relatively less stress is placed on academic success. Consequently, students have more chances to evaluate themselves in terms of how well they have learnt rather than how well they have performed in a domain. This facilitative learning environment may therefore prompt the development of more adaptive, healthy and positive schematic selves in learning mathematics.

Taken together, due to the differences in cultural values, educational opportunities and assessment practices, learning in these two cultures will inevitably lead to different experiences and hence a different understanding of one's identity. The discussion above provides a tentative answer explaining the differences between the corresponding schematic groups of students in these two cultures. Further studies are certainly required to examine how cultural values, social norms, school evaluative practice have contributed to the development of students' academic self-schemas and their associated learning patterns.

The current educational reform in Hong Kong (Education Commission, 2000) has removed a major public examination for secondary students in order to craft a new schooling structure in both secondary and tertiary levels. While the removal of a major public examination will substantially reduce the pressure of examination, Chinese students are still facing keen competition for university entrance and the focus on relative performance will continue to 
impact on the development of students' academic self-schemas through various forms of schooling practices and social norms on relative performance, resulting inevitably in dampening the development of positive schematics and aggravating the negative selves among students who have already developed a negative self. Undoubtedly, more reformative efforts and measures are required to promote lifelong learning and prevent prematurely channelling students away from mathematics learning due to the development of a negative identity. 


\section{References}

Alexander, P. A. (1997). Knowledge-seeking and self-schema: A case for motivational dimensions of exposition. Educational Psychologist, 32 (2), 83-94.

Ames, C. (1992). Achievement goals and the classroom motivational climate, in D. H. Schunk \& J. L. Meece (Eds.), Student perceptions in classroom (pp. 327-348). Hillsdale, NJ: Lawrence Erlbaum.

Banting, L. K., Dimmock, J. A., \& Lay, B.S. (2009). The role of implicit and explicit components of exerciser self-schema in the prediction of exercise behaviour. Psychology of Sport and Exercise, 10 (1), 80-86.

Biggs, J. (1987). Student approaches to learning and studying. Melbourne: Australian Council for Educational Research.

Biggs, J. (1996). The assessment scene in Hong Kong. In J. Biggs (Ed.), Testing: To educate or to select? Education in Hong Kong at the crossroads (pp. 3-12). Hong Kong: Hong Kong Educational Publishing Co.

Catrambone, R., \& Markus, H. (1987). The role of self-schemas in going beyond the information given. Social Cognition, 5 (4), 349-368.

Crombie, G., Sinclair, N., Silverthorn, N., Byrne, B. M., Dubois, D. L. \& Trinneer, A. (2005). Predictors of young adolescents' math grades and course enrolment intentions: gender similarities and differences. Sex Roles, 52, 351-367.

Cross, S. E., \& Markus, H. R. (1994). Self-schemas, possible selves, and competent performance. Journal of Educational Psychology, 86 (3), 423-438.

Chan, S. C. (1999). Same or different: A comparison of the learning beliefs and behaviours of Australian and Chinese university students. Unpublished $\mathrm{PhD}$ Thesis, Faculty of Education, Monash University, Melbourne.

Dowson, M., \& McInerney, D. M. (2001). Psychological parameters of students' social and work avoidance goals: A qualitative investigation. Journal of Educational Psychology, 93 (1), 35-42.

Eccles, J., Adler, T. F., Futterman, R., Goff, S. B., Kaczala, C. M., Meece, J. L. \& Midgley, C. (1985). Self-perceptions, task perceptions, socializing influences and the decision to enroll in mathematics. In S. F. Chipman, L. R. Brush, \& D. M. Wilson (Eds.), Women and mathematics: balancing the equation (p. 95-121). Hillsdale, NJ: Lawrence Erlbaum Associates.

Education Commission (2000). Reform proposals for the education system in Hong Kong. Hong Kong: Printing Department.

European Commission (2004). Progress towards the common objectives in education and training: indicators and benchmarks. Brussels: European Commission.

Garcia, T., \& Pintrich, P. R. (1993). Self-schemas, motivational strategies, and self-regulated learning. Paper presented at the annual meeting of the American Educational research Association, Atlanta, GA.

Garcia, T., \& Pintrich, P. R. (1994). Regulating motivation and cognition in the classroom: The role of self-schemas and self-regulatory strategies. In D. H. Schunk \& B. H. Zimmerman (Eds.), Self-regulation of learning and performance: Issues and educational applications (pp. 127-153). Hillsdale, NJ: Lawrence Erlbaum.

Hamo-Lyons, L. (1999). Implication of the "examination culture" for (English language) education in Hong Kong. In V. Crew, V. Berry, \& J. Hung (Eds.), Exploring diversity in the language curriculum (pp. 133-140). Hong Kong: Hong Kong Institute of Education.

Hannover, B. \& Kuhnen, U. (2004). Culture, context, and cognition: The Semantic procedural Interface model of the self. European Review of Social Psychology, 15 (1), 297-333.

Hau, K. T., \& Salili, F. (1991, April 3-7). Information value of teachers' evaluative behavior on perceived ability and effort among Chinese students. Paper presented at the Annual Meeting of the American Educational Research Association, Chicago. 
Jung, J., \& Lennon, S. J. (2003). Body image, appearance self-schema, and media images. Family and Consumer Science Research Journal, 32 (1), 27-51.

Kendzierski, D. (1988). Self-schemata and exercise. Basic and Applied Social Psychology, 9, 45-59.

Kendzierski, D. (1990). Exercise self-schemata: Cognitive and behavioral correlates. Health Psychology, 9, 69-82.

Liu, H. K. (1997). Secondary school students' approaches to learning mathematics. Unpublished PhD thesis, University of Queensland, Brisbane, Australia.

Kendzierski, D., \& Whitaker, D. J. (1997). The role of self-schema in linking intentions with behavior. Personality and Social Psychology Bulletin, 23, 139-147.

Kobal, D. \& Musek, J. (2001). Self-concept and academic achievement: Solvenia and France. Personality and Individual Differences, 30, 887-899.

Markus, H. (1977). Self-schemata and processing information about the self. Journal of Personality and Social Psychology, 35 (2), 63-78.

Markus, H., \& Kitayama, S. (1991). Culture and the self: Implications for cognition, emotion, and motivation. Psychological Review, 98 (2), 224-253.

Markus, H., \& Kitayama, S. (2010). Cultures and Selves: A Cycle of Mutual Constitution. Perspectives on Psychological Science, 5 (4), 420-430.

Markus, H., \& Smith, J. (1981). The influence of self-schema on the perception of others. In N. Cantop \& J. F. Kihlstrom (Eds.), Personality, cognition, and social interaction (pp. 233-262). Hilldale, New Jersey: Lawrence Erlbaum.

McPhan, G., Morony, W., Pegg, J., Cooksey, R., \& Lynch, T. (2008). Maths? Why not? Canberra: Department of Education, Employment and Workplace Relations.

Meece, J. L., Blumenfeld, P. C. \& Hoyle, R. H. (1988). Students' goal orientations and cognitive engagement in classroom activities. Journal of Educational Psychology, 80 (4), 514-523.

Murphy, P. K., \& Alexander, P. A. (2000). A motivated exploration of motivation terminology. Contemporary Educational Psychology, 25, 3-53.

Muzzatti, B. \& Agnoli, F. (2007). Gender and mathematics: attitudes and stereotype threat susceptibility in Italian children. Developmental Psychology, 43, 747-758.

Nagy, G., Watt, H. M. G., Eccles, J. S., Trautwein, U., Ludtke, O., \& Baumert, J. (2010). The development of students' Mathematics self-concept in relation to gender: Different countries, different trajectories? Journal of Research on Adolescence, 20 (2), 482-506.

$\mathrm{Ng}, \mathrm{C} . \mathrm{H}$. (2005). Academic self-schemas and contrasting self-congruent learning patterns: Findings validated with culturally different samples. Social Psychology of Education, 8, 303-328.

$\mathrm{Ng}, \mathrm{C}$. H. (2009). "Learning for achievement" as a collective motive in re-culturing learning and teaching in Hong Kong classrooms. In C. H. Ng \& P. D. Renshaw (Eds.), Reforming learning: Concepts, issues and practice in the Asia-pacific region (pp. 255-276). The Netherlands: Springer.

Oyserman, D., \& Markus, H. R. (1993). The sociocultural self. In J. Suls (Ed.), Psychological perspectives on the self: The self in social perspective (Vol. 4, pp. 187-220). Hillsdale, NJ: Lawrencwe Erlbaum.

Pintrich, P. R. (1994). Continuities and discontinuities: Future development for research in educational psychology. Educational Psychologist, 29 (3), 137-148.

Reiss, M., Hoyles, C., Mujtaba, T., Riazai-Farzad, B., Rodd, M., Simon, S., \& Stylianidou, F. (2011). Understanding participation rates in post-16 mathematics and physics: Conceptualising and operationalising UPMAP project. International Journal of Science and Mathematics Education, 9 (2), 273-302.

Uerz, D., Dekkers, H. \& Beguin, A. (2004). Mathematics and language skills and the choice of science subjects in secondary education. Educational Research and Evaluation, 10, 163-182.

Van Langen, A., Rekers-Mombarg, L. \& Dekkers, H. (2008). Mathematics and science choice following introduction of compulsory study profiles into Dutch secondary education. British Educational Research Journal, 34, 733-745. 
Watt, H. M. G. (2004). Development of adolescents' self perceptions, values and task perceptions according to gender and domain in $7^{\text {th }}$ through $11^{\text {th }}$ grade Australian students. Child Development, 75, 1556-1574.

Wigfield, A., \& Eccles, J. (1992). The development of achievement task values: A theoretical analysis. Developmental Review, 12, 265-310.

Young, A. J. (1997). I think, therefore I'm motivated: the relations among cognitive strategy use, motivational orientation and classroom perceptions over time. Learning and Individual Differences, 9 (3), 249-283.

\section{About the Author}

Dr. Clarence $\mathrm{Ng}$

My research work focuses on motivation and learning. I have previously completed research projects investigating the relationships between academic self-schemas, motivational goals, and learning. Currently, I am working on a large project exploring students' motivation for engaging in and avoiding reading. 



\section{JOURRNAL Of LEARNING}

\section{Editors}

Mary Kalantzis, University of Illinois, Urbana-Champaign, USA.

Bill Cope, University of Illinois, Urbana-Champaign, USA.

\section{Editorial Advisory Board}

Michael Apple, University of Wisconsin, Madison, USA.

David Barton, Lancaster University, Milton Keynes, UK.

Mario Bello, University of Science, Cuba.

Manuela du Bois-Reymond, Universiteit Leiden, Leiden, The Netherlands.

Bill Cope, University of Illinois, Urbana-Champaign, USA.

Robert Devillar, Kennesaw State University, Kennesaw, USA.

Daniel Madrid Fernandez, University of Granada, Spain.

Ruth Finnegan, Open University, Milton Keynes, UK.

James Paul Gee, University of Wisconsin, Madison, USA.

Juana M. Sancho Gil, University of Barcelona, Barcelona, Spain.

Kris Gutierrez, University of California, Los Angeles, USA.

Anne Hickling-Hudson, Queensland University of Technology, Kelvin Grove, Australia.

Roz Ivanic, Lancaster University, Lancaster, UK.

Paul James, RMIT University, Melbourne, Australia.

Carey Jewitt, Institute of Education, University of London, London, UK.

Mary Kalantzis, University of Illinois, Urbana-Champaign, USA.

Andeas Kazamias, University of Wisconsin, Madison, USA.

Peter Kell, University of Wollongong, Wollongong, Australia.

Michele Knobel, Montclair State University, Montclair, USA.

Gunther Kress, Institute of Education, University of London, London, UK.

Colin Lankshear, James Cook University, Cairns, Australia.

Kimberly Lawless, University of Illinois, Chicago, USA.

Sarah Michaels, Clark University, Worcester, USA.

Jeffrey Mok, Miyazaki International College, Miyazaki, Japan.

Denise Newfield, University of Witwatersrand, Johannesburg, South Africa.

Ernest O'Neil, Ministry of Education, Sana'a, Yemen.

José-Luis Ortega, University of Granada, Granada, Spain.

Francisco Fernandez Palomares, University of Granada, Granada, Spain.

Ambigapathy Pandian, Universiti Sains Malaysia, Penang, Malaysia.

Miguel A. Pereyra, University of Granada, Granada, Spain.

Scott Poynting, Manchester Metropolitan University, Manchester, UK.

Angela Samuels, Montego Bay Community College, Montego Bay, Jamaica.

Michel Singh, University of Western Sydney, Sydney, Australia.

Helen Smith, RMIT University, Melbourne, Australia.

Richard Sohmer, Clark University, Worcester, USA.

Brian Street, University of London, London, UK.

Giorgos Tsiakalos, Aristotle University of Thessaloniki, Thessaloniki, Greece.

Salim Vally, University of Witwatersrand, Johannesburg, South Africa.

Gella Varnava-Skoura, National and Kapodistrian University of Athens, Greece.

Cecile Walden, Sam Sharpe Teachers College, Montego Bay, Jamaica.

Nicola Yelland, Victoria University, Melbourne, Australia.

Wang Yingjie, Beijing Normal University, Beijing, China.

Zhou Zuoyu, Beijing Normal University, Beijing, China.

Please visit the Journal website at http://www.Learning-Journal.com for further information about the Journal or to subscribe. 


\section{The Learner Community}

This knowledge community is brought together by a common concern for learning and an interest to explore new educational possibilities. The community interacts through an innovative, annual face-to-face conference, as well as year-round virtual relationships in a weblog, peer reviewed journal and book imprint - exploring the affordances of the new digital media. Members of this knowledge community include academics, teachers, administrators, policy makers and other education practitioners.

\section{Conference}

Members of the Learner Community meet at The International Conference on Learning, held annually in different locations around the world, each selected for the particular role education is playing in social, cultural and economic change.

In recent years, the Conference has been held with Universiti Sains Malaysia, Penang, Malaysia in 1999; RMIT University, Melbourne, Australia in 2000; the University of Athens, Spetses, Greece in 2001; Beijing Normal University, Beijing, China in 2002; Institute of Education, London University, London, UK in 2003; Institute of Pedagogical Sciences, Havana, Cuba in 2004; University of Granada, Granada, Spain in 2005; Sam Sharpe Teachers College, Montego Bay, Jamaica in 2006; University of the Witwatersrand, Johannesburg, South Africa in 2007; the University of Illinois, Chicago, USA in 2008; the University of Barcelona, Spain in 2009; Hong Kong Institute of Education, Hong Kong in 2010; and the University of Mauritius, Mauritius in 2011. In 2012 the Conference will be held at The Institute of Education, University of London, London, UK.

Our community members and first time attendees come from all corners of the globe. Intellectually, our interests span the breath of the field of education. The Conference is a site of critical reflection, both by leaders in the field and emerging scholars and teachers. Those unable to attend the Conference may opt for virtual participation in which community members can either or both submit a video or slide presentation with voiceover, or simply submit a paper for peer review and possible publication in the Journal.

Online presentations can be viewed on YouTube.

\section{Publishing}

The Learner Community enables members to publish through three mediums.

First, by participating in the Learning Conference, community members can enter a world of journal publication unlike the traditional academic publishing forums - a result of the responsive, non-hierarchical and constructive nature of the peer review process. The International Journal of Learning provides a framework for double-blind peer review, enabling authors to publish into an academic journal of the highest standard.

The second publication medium is through the book series The Learner, publishing cutting edge books on education in print and electronic formats. Publication proposals and manuscript submissions are welcome.

The third major publishing medium is our news blog, constantly publishing short news updates from the Learner Community, as well as major developments in the field of education. You can also join this conversation at Facebook and Twitter or subscribe to our email Newsletter. 


\section{Common Ground Publishing Journals}

\begin{tabular}{|c|c|}
\hline $\begin{array}{l}\text { AGING } \\
\text { Aging and Society: An Interdisciplinary Journal } \\
\text { Website: http://AgingAndSociety.com/journal/ }\end{array}$ & $\begin{array}{c}\text { ARTS } \\
\text { The International Journal of the Arts in Society. } \\
\text { Website: www.Arts-Journal.com }\end{array}$ \\
\hline $\begin{array}{c}\text { BOOK } \\
\text { The International Journal of the Book } \\
\text { Website: www.Book-Journal.com }\end{array}$ & $\begin{array}{c}\text { CLIMATE CHANGE } \\
\text { The International Journal of Climate Change: } \\
\text { Impacts and Responses } \\
\text { Website: www.Climate-Journal.com }\end{array}$ \\
\hline $\begin{array}{c}\text { CONSTRUCTED ENVIRONMENT } \\
\text { The International Journal of the } \\
\text { Constructed Environment } \\
\text { Website: www.ConstructedEnvironment.com/journal }\end{array}$ & $\begin{array}{c}\text { DESIGN } \\
\text { Design Principles and Practices: } \\
\text { An International Journal } \\
\text { Website: www.Design-Journal.com }\end{array}$ \\
\hline $\begin{array}{c}\text { DIVERSITY } \\
\text { The International Journal of Diversity in } \\
\text { Organizations, Communities and Nations } \\
\text { Website: www.Diversity-Journal.com }\end{array}$ & $\begin{array}{l}\text { FOOD } \\
\text { Food Studies: An Interdisciplinary Journal } \\
\text { Website: http://Food-Studies.com/journal/ }\end{array}$ \\
\hline $\begin{array}{c}\text { GLOBAL STUDIES } \\
\text { The Global Studies Journal } \\
\text { Website: www.GlobalStudiesJournal.com }\end{array}$ & $\begin{array}{c}\text { HEALTH } \\
\text { The International Journal of Health, } \\
\text { Wellness and Society } \\
\text { Website: www.HealthandSociety.com/journal }\end{array}$ \\
\hline $\begin{array}{c}\text { HUMANITIES } \\
\text { The International Journal of the Humanities } \\
\text { Website: www.Humanities-Journal.com }\end{array}$ & $\begin{array}{c}\text { IMAGE } \\
\text { The International Journal of the Image } \\
\text { Website: www.Onthelmage.com/journal }\end{array}$ \\
\hline $\begin{array}{l}\text { LEARNING } \\
\text { The International Journal of Learning. } \\
\text { Website: www.Learning-Journal.com }\end{array}$ & $\begin{array}{c}\text { MANAGEMENT } \\
\text { The International Journal of Knowledge, } \\
\text { Culture and Change Management. } \\
\text { Website: www.Management-Journal.com }\end{array}$ \\
\hline $\begin{array}{c}\text { MUSEUM } \\
\text { The International Journal of the Inclusive Museum } \\
\text { Website: www.Museum-Journal.com }\end{array}$ & $\begin{array}{c}\text { RELIGION AND SPIRITUALITY } \\
\text { The International Journal of Religion and } \\
\text { Spirituality in Society } \\
\text { Website: www.Religion-Journal.com }\end{array}$ \\
\hline $\begin{array}{c}\text { SCIENCE IN SOCIETY } \\
\text { The International Journal of Science in Society } \\
\text { Website: www.ScienceinSocietyJournal.com }\end{array}$ & $\begin{array}{c}\text { SOCIAL SCIENCES } \\
\text { The International Journal of Interdisciplinary } \\
\text { Social Sciences } \\
\text { Website: www.SocialSciences-Journal.com }\end{array}$ \\
\hline $\begin{array}{c}\text { SPACES AND FLOWS } \\
\text { Spaces and Flows: An International Journal of } \\
\text { Urban and ExtraUrban Studies } \\
\text { Website: www.SpacesJournal.com }\end{array}$ & $\begin{array}{c}\text { SPORT AND SOCIETY } \\
\text { The International Journal of Sport and Society } \\
\text { Website: www.sportandsociety.com/journal }\end{array}$ \\
\hline $\begin{array}{c}\text { SUSTAINABILITY } \\
\text { The International Journal of Environmental, Cultural, } \\
\text { Economic and Social Sustainability } \\
\text { Website: www.Sustainability-Journal.com }\end{array}$ & $\begin{array}{c}\text { TECHNOLOGY } \\
\text { The International Journal of Technology, } \\
\text { Knowledge and Society } \\
\text { Website: www.Technology-Journal.com }\end{array}$ \\
\hline $\begin{array}{c}\text { UBIQUITOUS LEARNING } \\
\text { Ubiquitous Learning: An International Journal } \\
\text { Website: www.ubi-learn.com/journal/ }\end{array}$ & $\begin{array}{l}\text { UNIVERSITIES } \\
\text { Journal of the World Universities Forum } \\
\text { Website: www.Universities-Journal.com }\end{array}$ \\
\hline
\end{tabular}

